\title{
HUACAS LIMEÑAS: ANCESTROS AMAZÓNICOS Acerca de la presencia de pueblos del grupo etnolingüístico arawak en la costa central prehispánica a través de la toponimia
}

\author{
Pedro Carlos VARgas Nalvarte ${ }^{1}$ \\ UnIVERSIDAD NACIONAL MAYOR DE SAN MARCOS \\ pecavana@gmail.com
}

\section{RESUMEN}

Existe evidencia etnohistórica y arqueológica acerca de diversas divinidades que fueron adoradas en la costa central prehispánica. Sin embargo, entender su origen y detalles del culto resulta difícil debido a la escueta información y la ausencia de un adecuado cruce de ambas fuentes. Pero, ahora disponemos de estudios etnográficos realizados con informantes del pueblo Yanesha de la selva central que nos muestran un fluido contacto entre costa y selva central; esto ayuda a entender la real dimensión de las, en apariencia, divinidades costeñas; a su vez, conjugando toda la evidencia queda claro que la interacción entre la Amazonía y la costa central fue algo más que simples relaciones comerciales. Presentaremos evidencia que respalda la idea que al menos dos divinidades costeñas tienen como referentes a ancestros amazónicos de grupos Arawak y que existió una ruta entre territorio Ashaninka y el más famoso santuario costeño: Pachakamak.

Palabras clave: Costa central, sociedades costeñas, pueblos arawak, toponimia, antroponimia.

\section{Abstract}

There ethnohistorical and archaeological evidence about various deities were worshiped in preHispanic central coast. However, understanding their origin and details of worship is difficult because of the terse information and the absence of a suitable crossing from both sources. But now we have ethnographic studies with informants Yanesha village in the central jungle that show a fluid contact between coast and central jungle; this helps to understand the real dimension of apparently coastal

1. Licenciado en Arqueología de la Universidad Nacional Mayor de San Marcos. Miembro de la Asociación Peruana de Arte Rupestre (APAR). 
divinities; in turn, combining all the evidence is clear that the interaction between the Amazon and the central coast was more than just trade relations. Present evidence supporting the idea that at least two coastal divinities are as referring to Amazonian ancestors of Arawak groups and that there was a route between Ashaninka territory and the most famous coastal sanctuary : Pachakamak.

Keywords: Central Coast, coastal societies, Arawak peoples, toponimy, anthroponomy.

"Muy ingenuo es empeñarse en sacar el significado de ciertos nombres arcaicos de dioses o pueblos, solo desde el kechua o el aymara..."

(Julio C. Tello, 1999: 48)

\section{INTRODUCCIÓN}

En la última década hemos prestado particular interés a diversos aspectos de la religiosidad y sistemas de comunicación de los pueblos de la costa central, en particular de la Cultura Lima (200 - 700 d.C.); en la búsqueda de mayor información recurrimos a la etnohistoria donde hallamos divinidades cuyos periplos se desarrollan no sólo en la costa (Pachakamak, Urpaywachak), sino que irrumpen o vienen de la sierra (Kuniraya Wiraqocha) o escapan a la selva (Wallallu Qarwinchu), lo cual, pensamos, podría indicar un pálido reflejo de relatos más complejos que el desinterés de cronistas y extirpadores de idolatrías dejó en la forma que conocemos actualmente.

Por el año 2010 conocimos los trabajos que el Dr. Richard Smith, Director Ejecutivo del Instituto del Bien Común (IBC), venía desarrollando desde hace más de tres décadas con el pueblo Yanesha de la selva central; al escuchar la información que este investigador obtuvo vimos que existía una fuente aún no aprovechada para el estudio de la costa central prehispánica: la etnográfica. Sería injusto decir que nadie se había percatado en ello, ya María Rostworowski había presentado relatos ashaninkas y matsiguengas (Rostworowski, 2009: 38-41) para fundamentar las ramificaciones del culto a Pachakamak; sin embargo, era necesario aunar más información para tener una idea clara de lo que está ocurriendo entre los pueblos de la costa, sierra y selva central. Para ello es necesario de deshacerse de la idea de un Perú funcionando con tres franjas paralelas de costa, sierra y selva.

Para los efectos de este artículo presentaremos nuestros planteamientos generales, la metodología de trabajo, los antecedentes, una breve revisión a lo que se tiene acerca de lenguas prehispánicas en Lima, presentaremos la evidencia lingüística, la arqueológica, etnohistórica y etnográfica con la cual esperamos dar sustento a la hipótesis de Smith: la existencia de un sustrato de lenguas Arawak en las sociedades de Lima Prehispánica, sugerencia que plantea en su artículo del 2011 (Smith 2011: 247). Para motivos de este artículo abordaremos sólo dos nombres (un topónimo y una palabra que es parte de los nombres de varias divinidades) que, consideramos, resaltan por su importancia y vínculos con referentes actuales: 'Pucllana' y 'ñamka'.

\section{Planteamientos Generales}

En la costa y sierra central del Perú existen ciertos topónimos que no pertenecen al español ni a ninguna lengua de las familias quechua o aru, esto lleva a plantearse la interrogante acerca de la lengua a la cual pertenecen; siendo la costa central una importante zona de desarrollo cultural y de cruce de caminos es posible pensar en la existencia de lenguas anteriores a la expansión quechua y aru que hayan dejado su marca en la toponimia y antroponimia de la zona. Nuestro propósito principal en este artículo, por tanto, es averiguar a qué lenguas pertenecen los topónimos de la costa y sierra central que no están en español o lenguas quechuas o aru. Nuestro hipótesis, siguiendo los plantea- 
mientos e Smith (2011) es que pertenecen a lenguas del grupo etnolinguístico Arawak, consideradas actualmente amazónicas.

Desconocemos que lenguas se hablaron antes de la expansión de las lenguas de las familias quechua y aru, siendo la costa central un importante núcleo civilizatorio que ha mantenido contacto con diversas zonas geográficas, esto debería reflejarse de algún modo en su realidad lingüística. Tello ya había planteado que el origen de las culturas andinas y costeñas era amazónico y propone la existencia de lenguas de la familia Arawak en la costa central (1999); por otro lado, Alfredo Torero plantea un origen andino para las lenguas Arawak (1991, 2002); finalmente, Smith (2011) plantea que hubo presencia de lenguas Arawak en la costa y sierra central del Perú durante el Periodo Intermedio Temprano (200-700 d.C.) o incluso antes (Smith 2011: 246). Este trabajo permitirá ahondar en estas hipótesis proponiendo nuevas respuestas o desechando otras.

\section{Marco TeÓRICo}

El estudio de los topónimos es parte de la onomástica, entendida como el estudio de los nombres propios, sean de personas o lugares (Solís, 1997: 14), y constituyen una fuente importante de conocimiento de lenguas que pueden haberse extinguido o de pueblos cuyo rastro en la historia puede estar marcado sólo por topónimos.

Los topónimos pueden bien ser considerados una fuente histórica o un fuerte apoyo a ésta, como bien señala Solís:

“A veces el único medio que se tiene a la mano para esclarecer hechos, sobre todo los referidos a lo ocurrido en tiempos muy remotos o pueblos que no han dejado otra clase de huella de su paso por el mundo, que no sean los índices toponímicos. En la medida que los nombres permanecen a veces más tiempo que las lenguas que los originaron, los nombres toponímicos son hitos históricos..." (Solís, 1997: 20)

No sólo ello, sino que también los nombres toponímicos son susceptibles a cambios lingüísticos al igual que la lengua, pudiendo originarse más de una versión del nombre de un mismo referente, como es el caso de los dupletes toponímicos; también podemos observar variación en los nombres cuando hay cambios en el sistema de escritura, o sea la manera de representar de manera gráfica los sonidos de una determinada lengua. Esto puede tener mayores consecuencias cuando se usa un sistema de escritura hecho para cierta lengua y transcribir palabras de otra (Ibíd.:21)

Exponemos algunos principios mencionados por Solís (1997: 33-34), en relación a los topónimos, que pueden enrumbar nuestro trabajo:

- A mayor humanización del paisaje, mayor nominación y mayor cantidad de topónimos

- A menor humanización del paisaje, menor cantidad de topónimos

- A mayor tiempo de ocupación, mayor nominación

- A mayor nominación diacrónica, mayor oscuridad semántica de los topónimos

Consideraremos también las advertencias relacionadas a las falsas etimologías: "El factor principal de una falsa etimología es la errónea filiación lingüística de los topónimos” (Ibíd.: 37) De esto se colige que "Averiguar el étimo de cualquier topónimo pasa por la necesidad previa de identificar su pertenencia a una lengua X específica.” (Ibíd.) Y es también cuando hay mayor profundidad temporal que la etimología popular es más activa. 
Para lo referido a los procesos de reconstrucción fonológica y semántica nos basaremos en los principios de la lingüística histórica expuestos por Bynon (1981) donde también se resalta la importancia del estudio de los topónimos para la lingüística histórica, refiriéndose a nombres de accidentes geográficos que resisten el paso del tiempo y permanecen; cuando se da nombre a un lugar se hace de acuerdo a las normas de su lengua y esto permite decir que sus hablantes estuvieron allí (Bynon, 1981: 373).

Sin embargo, no siempre la falsa etimología o etimología popular es una falacia, pues es una interpretación que se realiza en base al conocimiento de la lengua propia de una realidad lingüística anterior; por tanto, dicha interpretación tiene validez en la medida que responde a la realidad temporal en la que fue hecha dicha interpretación. Cosa muy distinta es asumir que ese fue el significado original pudiendo ser el caso de que la palabra esté en una lengua distinta a las que se supondría hay en la zona estudiada.

Para averiguar el significado de un topónimo lo primero que debe realizarse es determinar a qué lengua pertenece y sólo luego de esto se puede aventurar lo que significa; obviamente, si fallamos en el primer paso, el resto será inválido. Un error muy común en los estudios toponímicos andinos es pretender reducir todo a sólo quechua o aymara, obviando otras lenguas. Esto ya fue observado por Tello (1999: 48) quien califica lo anterior de ingenuidad, y Taylor (1987: 7-8) quien sostiene que:

"La toponimia no se puede reducir únicamente a las dos lenguas principales: quechua y aru (...) el lenguaje ritual común a las dos lenguas, presente en el léxico del culto, en los nombres de los dioses, de las personas y de los objetos rituales, podrían, en efecto, remontarse a un estado de desarrollo de la cultura andina anterior a la dominación quechua y aru."

\section{La Costa y la SierRa de Lima}

El escenario geográfico de nuestra investigación se encuentra circunscrito a la costa central, entendiéndose por esta a los valles bajos de los ríos Chillón, Rímac y Lurín; además contemplaremos la vertiente occidental de los andes adyacentes a estos valles. Este paisaje está dominado por un desierto con bosques ribereños, lomas y humedales que fue convertido en valle gracias a inmensos trabajos de irrigación realizados por medio de la construcción de canales de dimensiones tales, que aún hoy son llamados ríos, como sucede con el 'río' Surco. La cordillera occidental el día de hoy debe ser un pálido reflejo de lo que documentos como el Manuscrito de Huarochirí mencionan al referirse a que pocos eran los cerros que no tenían terrazas para cultivos, sin contar con la presencia de bosques que debieron inspirar a los informantes de Ávila a hablar de bosques inmensos llenos de monos y loros.

El desarrollo histórico de la costa y sierra central es un tema complejo que ocuparía de por sí innumerables artículos. Las ocupaciones humanas más antiguas se encuentran en el valle del Chillón, en el Cerro Chivateros, así como en Ancón, correspondiendo estas al Periodo Lítico (10000 - 6000 a.C.). Durante el denominado Periodo Arcaico surgen las primeras aldeas y ya en el Formativo Inicial templos como El Paraíso, de clara influencia de la Civilización Caral ubicada más al Norte. Una construcción típica de la costa central será el llamado 'Templo en U', de amplia distribución entre los valles de Lurín al sur y Chancay al Norte, caracterizados estos por la presencia de una pirámide central y dos alas laterales que encierran una plaza. En estos templos será muy clara la influencia de la Cultura Chavín hacia el 1200 a.C. y algún tiempo más adelante. Es de resaltar la presencia de seres no natu- 
ralistas realizados siguiendo los cánones simbólicos de Chavín y también de felinos, seres humanos y lagartijas como el ídolo articulado de Mina Perdida (recordar este último detalle). Tras un confuso periodo caracterizado por la presencia de una cerámica decorada con colores rojo y blanco se da paso al periodo de los Desarrollos Regionales (200 - 700 d.c.) caracterizado por la construcción de enormes pirámides alargadas en base a adobitos y tapiales que demuestran el alto desarrollo social logrado por los antiguos limeños. Hacia el 650 d.C. se deja sentir una influencia de la costa y sierra Sur que marca el inicio del Periodo Wari, hacia el final de esta época la influencia vendrá desde el norte. Cuando esta influencia se desvanece se notará el resurgimiento de lo local en la llamada cultura Ychsma, tiempo durante el cual la costa central disfrutará de autonomía y gran prestigio por el Oráculo de Pachacamac. Tras la conquista por el imperio cusqueño la costa central pasará a ser administrada como una provincia imperial sujeta a los requerimientos de la nobleza cusqueña.

Lima se encuentra en la zona del Quechua I o central (Torero, 2002: 59) esta zona se extiende en la sierra central del Perú, entre los $8^{\circ} 25^{\prime}$ y $13^{\circ} 05^{\prime}$ de latitud sur ocupando el área de los departamentos de Ancash y Huánuco al Norte, Pasco, Junín y Lima al Sur y las zonas noreste y noroeste de Ica y Huancavelica, respectivamente (Ibíd.). Este mismo espacio geográfico es considerado el escenario de la primera expansión del quechua más la franja costera adyacente (Ibíd.: 86). Torero presenta una serie de razones por las cuales se fundamentaría esto; una de ellas es "La exclusividad de la explicación mediante el quechua de la toponimia del área así definida, descontados los topónimos castellanos y los, escasos, que no hallan explicación en ninguna lengua previsible" (Ibíd.). Veremos más adelante que podemos definir que algunos topónimos y antropónimos son claramente Arawak. Sin embargo, ante esto es necesario tomar en cuenta que este mismo autor plantea que las lenguas Arawak pudieron tener su origen en los andes (Ibíd.: 35 ) además menciona que los nombres de las divinidades andinas parecen proceder de lenguas consideradas actualmente amazónicas (Ibíd.: 1991).

Planteando el origen del quechua para la costa norcentral (Ibíd::86) deja a la costa central como un espacio libre para la existencia de otra (s) lengua (s) que, pudieron haber estado siendo presionadas por el quechua, siendo finalmente expulsadas o dejadas de lado. Algo parecido plantea Smith "Sabemos que la lengua yanesha y el quechua Yaru interactuaron intensivamente durante un largo tiempo en lo que parece haber sido una situación de expansión del quechua frente a una retirada del proto-yanesha." (2011: 247).

Es muy interesante una mención en la crónica de Anello Oliva (1895:15, citado por Torero, 2002: 26) donde se menciona que las lenguas particulares (en contraposición a las generales como el quechua o el aymara) se conservaban "...en algunos pueblos tan tenazmente que no se habla sino la propia y nativa que tienen como en el pueblo de Lambaieque, en los llanos de Lima y en algunos pueblos de la provincia de Chucuito la lengua Puquina." (Resaltado nuestro) Lo que es realmente interesante es la mención a una lengua particular en Lima, lo lamentable es que no se mencione el nombre de la lengua.

Tello (1999: 27-28) realiza avezadas propuestas acerca de las lenguas habladas en Lima, sostiene que existieron dos naciones que tuvieron sus propias lenguas, ambas claramente costeñas. La nación Karwa se extendería desde el norte del Rímac hasta Ancón y la nación Limak al sur del Rímac hasta Pachacamac. Dejando de lado la confusión que el texto (no preparado para su publicación) muestra, es notorio remarcar que Tello sostenga, a nuestro parecer, acertadamente; que los nombres de las divinidades se encuentran en lenguas tan diversas como el quechua, el aymara que procederían de un tronco Acaru y lenguas del litoral como Muchik y Pukina. Todo esto respondería a la existencia de diversas ondas lingüísticas, lo cual indicaría movimiento de poblaciones. 


\section{ANTECEDENTES}

Si bien no existen estudios acerca de la toponimia antroponimia de Lima, se encuentran algunas menciones aisladas en trabajos etnohistóricos donde el objetivo es conocer si tal o cual población estuvo instalada en un determinado territorio. Sin embargo, creemos que partiendo de nuestra hipótesis relacionada a la presencia de lenguas arawak en la costa central podemos contribuir sobre la presencia de lenguas o pueblos amazónicos en Lima.

Lima está calificada como parte nuclear del quechua I (Torero 2002. 76 - 78) y como tal puede pensarse que siempre lo ha sido, pero, desde inicios del siglo XX se planteaba la posibilidad de una influencia amazónica e incluso que el origen de las civilizaciones andinas y costeñas estuvo en la Amazonía, esto fue planteado por Tello (1929: 21 -22)

"Es más razonable pensar que el salvaje de la floresta - a quien se atribuye el conocimiento de ciertas formas primitivas de agricultura, hubiera obtenido en los valles trasandinos el cultivo de ciertas plantas como la yuca, el camote, el maíz, la lagena, el zapallo, el pallar, etc. Y lo hubiera propagado a las tierras yunkas interandinas, cisandinas y a los valles del litoral."

Tello y Mejía Xesspe (1979: 7-8) señalan, en el caso específico del centro andino, dos idiomas principales, uno a cada flanco de la cordillera: los del lado oriental son vinculados al quechua relacionados a la lengua arawak y para los del lado occidental el Jacaru, pero, de este se dice “... cuyas raíces tienen vinculaciones con las ramas arcaicas del arawak" (Ibíd.: 8) Queda claro que para los autores las lenguas del flanco occidental responden a una antigua influencia arawak de la cual apenas quedarían vestigios en lenguas que ya pueden considerarse ahora como andinas.

En textos que no fueron publicados en vida de Tello ni ninguno de sus asistentes se encuentra información interesante acerca de vínculos con la familia arawak de parte de los pueblos de la costa y sierra de Lima, en un manuscrito de la década del treinta del siglo pasado, publicado en 1999, se menciona que "Es posible que yungas o habitantes del litoral, de origen uropukina o arawak, hayan formado la nación de Limak, y yungas de origen Tallán o Caribe, las de Karwa”. (Tello, 1999: 27).

También se menciona que las lenguas de la costa como la muchik o la pukina están “...relacionadas con las lenguas forestales..." (Ibíd.: 48). El vínculo del puquina con las lenguas arawak era algo claro para Tello y también para Torero (2002: 35) además ambos relacionan lenguas no clasificadas como el muchik con la Amazonía (Ibíd.) Debemos recordar que Julio C. Tello fue un pionero en el estudio de la lengua yanesha (amuesha) y si bien el total de sus trabajos no han sido publicados hasta hoy, debe existir en sus archivos documentos de trabajo que avalen muchas de sus afirmaciones con evidencia adecuada.

Si bien tiempo después que Tello expusiera sus ideas, se ha hablado mucho acerca del origen amazónico de las culturas andinas (Lahtrap, por citar un ejemplo), el tema no ha sido profundizado desde el lado arqueológico y mucho menos lingüístico hasta el 2011. Tras tres décadas de trabajo de campo y gabinete con el pueblo yanesha, el antropólogo Richard Smith plantea la sugerente propuesta de que existe un sustrato arawak en los andes centrales, sin embargo, inicialmente consideró que el pueblo yanesha tenía un sustrato andino (Smith, 2011:221). Luego, esto variará y se manifestará que:

"Hoy, con mucha evidencia nueva, sobre todo una visión mucho más completa de la historia oral yanesha, combinada con un mapeo de la ubicación precisa de miles de lugares relacionados con personajes ancestrales yanesha, me atrevo a sugerir como hipótesis la existencia de un sustrato arawak en los orígenes de la civilización en los andes centrales del Perú (Smith, 
2006). Ese sustrato incluiría a los antepasados de los yanesha, yunka, ashaninka y otros pueblos quienes ocupaban una franja transversal desde la costa de Lima y Pachacamac hasta la selva del Pachitea, Perené y Alto Ucayali." (Ibíd.)

Smith sustenta su hipótesis con evidencia arqueológica, etnohistórica y relacionada con la red de caminos que permiten comprobar que la accesibilidad era buena entre costa y sierra.

Las investigaciones acerca de la presencia de lenguas amazónicas en Lima se reducen a lo presentado, dentro de esto sólo hay menciones pequeñas a los estudios de toponimia, entre las que resaltamos los consejos de Tello de no reducir todo al quechua o al aymara y la sugerencia de Smith de:

“... la historia oral yanesha sugiere que ellos y los yunka fueron pueblos emparentados lingüísticamente. Eran descendientes de los mismos ancestros tutelares que entendían indistintamente la lengua de uno y de otro. (En nota a pie de página: Un estudio de los topónimos de los valles del Chillón, Rímac y Lurín podría ayudar a comprobar este supuesto)”. (Ibíd.: 246-247)

\section{PULIANA - JULIANA - PUCLLANA - POCYENA}

Huaca Pucllana fue un importante centro ceremonial de la Cultura Lima que dominó la margen izquierda del valle bajo del río Rímac en tierras irrigadas en parte por el canal Surco y en parte por el canal Huatica. Conformado inicialmente por dos edificios piramidales acompañados de patios con banquetas, sistemas de acceso en rampa y recintos interconectados. Tuvo su tiempo de vigencia a finales del Periodo Intermedio Temprano e inicios del Horizonte Medio (450 - $650 \mathrm{dC}$ ). La evidencia recuperada por la Dra. Isabel Flores y su equipo desde 1981 nos muestra un mundo religioso dominado por la creencia en el mar como una divinidad femenina acompañada por una corte de seres marinos como tiburones, pulpos, anguilas, aves guaneras, nutrias, entre otros. Son numerosos los restos de mujeres sacrificadas en rituales asociados a cambios en la arquitectura. Estos sacrificios son particularmente violentos (Barreto et al 2010; Barreto 2012). Los entierros evidencian que la mujer tiene un estatus igual o mayor que el varón; esto resultaría muy lógico en un centro ceremonial dedicado a una divinidad femenina.

Sin embargo, lo que nos preocupa aquí es el origen del nombre. Para esto, seguiremos a Bacigalupo (1999) quien sustenta el nombre de Huaca Pucllana para este sitio arqueológico. Es, originalmente, la etnohistoriadora María Rostworowski, quien da a conocer documentos burocráticos de compra y venta de tierras en Lima en el S. XVI donde se menciona un 'cerro y huaca' denominado como Puliana (Bacigalupo 1999) y en un Derrotero Naval aparece como Huaca Pucllana (Ibíd.). Es a partir de estos datos que se plantea que el monumento que hasta la actualidad algunos conocen como 'Huaca Juliana' tenía por nombre original ‘Huaca Pucllana'. Bacigalupo (1999) presenta evidencia que respalda la propuesta del nombre siendo 'pucllana' un 'Lugar sagrado donde se juega' (Ibíd.: 134). Añade también información inédita de Lorenzo Huertas (Huertas 1983, citado por Bacigalupo 1999) que habla de la posibilidad que el nombre se refiera a burlas a los ritos católicos realizados en el abandonado centro ceremonial. Bacigalupo reconoce que este nombre puede ser la deformación de uno original y que, en todo caso, es el nombre con el que se le conoció tardíamente (Ibíd.: 133).

Casi como un dato para olvidar, Bacigalupo coloca al final de su artículo la mención a otro probable origen del nombre, siguiendo a Rafael Varón (Varón: 452, citado por Bacigalupo 1999) plantea la posibilidad que el nombre aluda a la presencia de estanques y ojos de agua que hasta unas décadas existían cerca del sitio arqueológico. Encuentra en el diccionario de Domingo de Santo Tomás la voz ‘pucyuymanan cusñaymanan' que significa 'manar la fuente agua'. Lamentablemente, no se ahonda más esta pista. 
Evidencia etnohistórica del Manuscrito Quechua de Huarochirí nos habla de una divinidad femenina antropomórfica ligada al mar, a los peces, las serpientes y las aves; conocida como Urpayhuachac ('la que pare palomas'), esta divinidad poseía todos los peces del mar en un estanque y sus hijas escapan del ultraje de una divinidad serrana convirtiéndose en palomas y de allí el origen de su nombre que, se infiere, oculta a otro anterior. Otra visión es la del mar como una divinidad conocida como Mamakocha, gran dispensadora de alimentos, adorada pero a la vez temida (Buse de la Guerra 1977). Siendo ambas versiones de los siglos XVI y XVII no necesariamente deben coincidir con la evidencia de Huaca Pucllana; pero, llama poderosamente la atención lo que nos muestra la evidencia etnográfica de la selva central.

Smith (2011: 244 - 245) nos habla de ancestros yanesha ligados al agua que se encuentran en Lima, uno de ellos nos es particularmente interesante:

"La femenina, Pocyena, es la que tiene a su cargo el cuidado del mar y otros cuerpos de agua y toda la vida animal que contienen. Está asociada a algunas enfermedades, especialmente las asociadas con algunas especies de sapos y pescados que habitan los ojos de agua. Dicen que Pocyena vive en un lugar alto desde donde se puede ver el mar: tentativamente se ha identificado la Huaca Pucllana como posible morada." (Smith 2011: 244).

En nota a pie de página Smith refiere sobre Pocyena que "Esta palabra es la personificación de Pocoy, un conjunto de enfermedades causadas por espíritus que habitan cuerpos de agua. Está relacionada al término quechua puquio, manantial." (Ibíd.) Esta información es la que, en nuestra opinión (planteada en Vargas 2014) sustenta de manera más firme la identidad del ser divino que durante el Intermedio Temprano e inicios del Horizonte Medio, fue adorado en el sitio arqueológico conocido como Huaca Pucllana. El dato mencionado tangencialmente por Bacigalupo (1999) era el que correspondía con la evidencia arqueológica hallada en Pucllana (Flores 2005 para una muestra de vasijas decoradas con tiburones, sacrificios femeninos e incluso una pequeña ofrenda de plumas de guacamayo).

Queda claro que Pocyena es el nombre de un ancestro femenino de los yánesha. Huaca Pucllana es el topónimo de un centro ceremonial Lima del Intermedio Temprano. Las características y atributos del ancestro coinciden con la evidencia material recuperada del sitio arqueológico. De acuerdo a esto los yanesha poseen la memoria histórica suficiente para remontarse a los siglos V al VII dC pues están describiendo los atributos de una divinidad de dicho tiempo. Esto no sería de extrañar pues Smith (2011: 246) plantea que la recurrencia de ciertos animales en la narrativa tradicional yanesha coincide con el arte figurativo y simbólico del periodo Formativo en la Costa central. Sin embargo, el nombre 'pocyena' es un derivado de una palabra quechua. Se puede pensar que lo que observamos es resultado de influencia de la costa central quechua hablante hacia la Amazonía; sin embargo, la compleja interacción del quechua con el yánesha merece más atención.

\section{RIMAK - LIMA - AMKAÑ - ÑAMA}

El denominado 'Manuscrito quechua de Huarochirí' es un documento colonial resultado de las campañas de extirpación de idolatrías efectuadas entre los finales de los siglos XVI e inicios del siglo XVII. El texto en mención fue redactado por un informante indígena quechuahablante, aunque se nota un sustrato aru. El destinatario del texto era el padre Francisco de Avila quien también estuvo redactando un tratado en base a estas informaciones, lamentablemente, inconcluso. El original se encuentra en la Biblioteca Nacional de Madrid y ha sido objeto de variadas traducciones y estudios. Se considera que fue redactado a inicios del siglo XVII y la información que brinda es valiosa y viable de ser contrastada con otras procedentes de documentos etnohistóricos o datos etnográficos. 
Hay información muy interesante sobre dioses, ancestros, migraciones, cambios en la geografía, la llegada del Inca y los españoles así como el impacto de la implantación del cristianismo católico. Para nuestros objetivos nos basaremos en la edición de Gerald Taylor (1987) y haremos uso de su sistema de separación de capítulos y enunciados (Ejemplo 4:2 es Capítulo 4, enunciado 2).

En esta ocasión nos centraremos en los nombres de las divinidades por una razón muy interesante: en el manuscrito hay diversas menciones a dioses que derrotan a otros así como sus relaciones de parentesco. Dado que los nombres de las divinidades pueden estar en lenguas que ya no se usaban en los tiempos que se redactó el manuscrito, su estudio de manera diacrónica es de suma importancia pues pueden brindar una especie de 'secuencia maestra' de lenguas para la zona de Huarochirí.

En términos simples podemos decir que en un inicio existían los dioses Tutañamka y Manañamka, estos fueron derrotados por Wallallu Qarwinchu, este a su vez fue derrotado por Paryakaka y su parentela; luego llegan dioses traídos por los señores del Cusco; de manera paralela se tiene a Kuniraya Wiraqucha y a Pachakamak con su familia. Por tanto podemos plantear secuencias de dioses en escenarios geográficos diversos y asociados a pueblos distintos.

De lo anterior debemos prestar especial atención a una raíz que aparece en las divinidades más antiguas, hablamos de la palabra 'ñamka'. En el quechua Junín - Huanca (Cerrón Palomino, 1976) se tiene ñanka como 'mujer poco hacendosa, ociosa' y ñankash como 'andariego'. En el diccionario aymara de Deza Galindo (1989) aparece ñanqha como 'airado, cruel, malo, vicio'. En el diccionario de Ludovico Bertonio (1993) aparece yanqha como 'mala cosa'. En jakaru (Belleza, 1995) tenemos ñamka o ñamki como 'tocar, palpar'. En Ludovico Bertonio (1993) también tenemos que 'tocar' es llamkaña. En el mapa de toponimia yanesha de la costa y sierra central (Smith, 2011) tenemos un ancestro llamado Tañ Amkañn, aquí esta última palabra significa 'agorero, agorera' (Duff - Tripp, 2008). La misma divinidad llamada Tamtañamca aparece en otro autor (Albornoz) como Tantanamoc, reconstruido por Taylor (1987: 87) como tamtañamuq, su ídolo estaba en Pachacamac y era una zorra de oro. Según Gustavo Solís (Taylor, 1987: 235) ñamoc es una variante de llamoc cuyo culto sobrevive en la región; también nos hizo notar (Solís, comunicación personal) que esta palabra aparece en el nombre de algunas divinidades en la "Relación de los agustinos de Huamachuco" (1992) tales como Agan Yamoc y Yamohuanca. Lo anterior en el caso de que namoc o ñamuq sea una derivación de llamoc; sin embargo, hay otra posibilidad y es que la palabra venga de una lengua de la costa norcentral como podría ser el quingnam, en esta lengua hallamos el nombre de un rey llamado Tacaynamo y una ciudad de nombre Pacatnamu; es probable que namo aquí signifique 'señor'.

Ahora la situación se torna muy complicada. Para lograr entender ñamca y buscarle un origen encontramos una diversidad de fuentes que no aclaran mucho las cosas a primera vista. En aymara, tanto Jacaru como del sur el significado es 'tocar, palpar'; podemos notar una alternancia entre $\tilde{n}$ y ll, cosa común que veremos luego también. Se tiene en Bertonio también yanqha 'cosa mala' y en Deza Galindo (1989) ñanqha como 'malo, airado y vicioso'. Esta connotación negativa aparece sólo en el aymara del sur, pudiendo haberse originado este significado luego de la expansión aymara hacia esta zona. Esto, pudo ser al mismo tiempo que pasa al quechua de Junín como ñanka 'mujer poco hacendosa' y ñankash 'andariego' ambos términos con una connotación negativa que de alguna manera puede ligarse con 'tocar, palpar'. Sin embargo, esto no suena muy convincente para el nombre de una divinidad. Queda claro que, hasta el momento el origen de la palabra es aru.

Culturalmente, tiene más sentido el significado de una palabra en yanesha, que aparece en el nombre de una divinidad y que es a su vez el nombre que ellos dan al río Rímac: amkañ cuyo significado es 'agorero, agorera' (Duff - Tripp, 2008, Smith, 2011) Aquí habría ocurrido que la ñ final pasó al inicio 
para acomodarse la palabra a la pronunciación aymara o quechua mediante el proceso de metatésis. Pero, el asunto se complica más pues la palabra ñamca aparece en una variante del nombre de estas divinidades yuncas con la siguiente variante: Tamtanamoc. Solís plantea que pasó del culle llamok al aymara como ñamok y luego al quechua como ñamka. Pero, tenemos que namo aparece en nombres de filiación cultural chimú, quienes habrían hablado una lengua que no era la muchik que sería el quingnam. Entre estos nombres tenemos: Tacaynamo (fundador de la dinastía chimu) y Pacatnamu (ciudad chimú); habiendo otros en diversas fuentes (Zevallos quiñones, 1992). Según Alfredo Torero (Torero, 2002: 223) el significado de namo sería 'señor' o 'padre'.

No nos convence el origen aymara de ñamca, la solución parece estar más por el lado del quingnam o el yanesha; sin embargo, el culle no debe ser dejado de lado pues debió compartir vocabulario con el quingnam. El substrato bajo el aymara en la costa y sierra central parece ser una mezcla de lenguas arawak con otras de filiación no definida.

De acuerdo a los estudios de Richard Smith (Smith, 2006, 2011) en la costa y sierra central del Perú existiría un sustrato cultural de pueblos actualmente amazónicos de la familia lingüística Arawak. Parte de los trabajos realizados de recopilación de tradiciones orales muestra un conocimiento grande respecto la realidad de la costa y sierra central, en particular del territorio que actualmente ocupa la ciudad de Lima. Se menciona que el río Rímac tiene por nombre Amcas, que es una derivación del nombre de un ancestro llamado Thañ Amcañ 'Abuelo Agorero'; curiosamente, el significado de Rímac es casi el mismo: 'el que habla, oráculo'. Más interesante aún es mencionar que la ubicación de este ancestro es en la confluencia de los ríos Rímac y Santa Eulalia, allí también se encuentra un ancestro femenino, su esposa, llamada Corarya 'Abuela Renacuajo' que da nombre al río Santa Eulalia como Coraryas. En este mismo lugar el Manuscrito de Huarochirí menciona la existencia del adoratorio y residencia de Manañamca, mujer de Huallallo Carhuincho, quien tras su derrota ve su adoratorio usurpado por Chaupiñamca, adscrita como hermana del vencedor Pariacaca. Vemos que el lugar está relacionado a la palabra ñamca o amcañ por dos tradiciones orales distintas. Ya hemos visto el proceso lingüístico de metátesis por el cual amcañ terminó como ñamca.

De ser esto así, tendríamos un conjunto de divinidades cuyos nombres giran en torno a su capacidad de predecir el futuro, como es muy común en las huacas de los pueblos yungas (verbigracia Pachacamac), tendríamos así: 'el agorero del collar de plumas' (Tamtañamca), 'el agorero de la noche' (Tutañamca), 'el agorero negro' (Yanañamca), 'la agorera del medio' (Chaupiñamca) y 'la que no es agorera' (Manañamca).

No existen mayores estudios lingüísticos que permitan definir el quingnam ni su área de expansión, debemos basarnos en la información recopilada por diversos cronistas que ha sido sintetizada por Alfredo Torero en su estudio acerca de las lenguas prehispánicas norteñas (Torero, 1986, 2002). Siguiendo a este autor el quingnam se habría hablado desde el valle de Chicama por el norte hasta el Santa por el sur, aunque el cronista Calancha sostiene que "... los vasallos de Pacasmayo dieron en hablar su lengua, y los demás hasta Lima." (Cita de Calancha en Torero, 2002: 216). Sin embargo, Bernabé Cobo plantea que esta lengua se habló hasta el valle de Carabaillo, muy cerca de Lima y no al norte de esta de acuerdo a Torero y la información poco clara de Calancha. En todo caso habría que revisar el resto de información antroponímica y toponímica para ver que tanto de quingnam podría haber en Lima y revisar la evidencia arqueológica referida a influencias norteñas o similitudes en la cultura material de costa central, norcentral y norte en diversas épocas.

En caso de tener la palabra ñamca un origen quingnam en namo, los significados no tendrían mucha 
del medio’ (pero ¡Chaupiñamca es mujerj), 'el que no es padre’ (referido a una huaca mujer tiene lógica pero no deja de ser extraño). No habría mayor apoyo desde el lado semántico para esta propuesta.

Sin embargo, en un cotejo general que realizamos de toponimia y teonimia que realizamos de la cuenca del Santa Eulalia, de acuerdo a información de 1920 recuperada por Tello y Miranda (1923), hallamos dos huacas con los siguientes nombres: Namoc y Namocoya, en este caso, la presencia de namo no está inferida o reconstruida sino que es directa.

De acuerdo a la propuesta de Solís ñamca sería derivación de ñamuq que a su vez vendría del culle llamok. Esta palabra aparece como parte del nombre de algunas divinidades mencionadas en la "Relación de los Agustinos de Huamachuco' (1992): Agan Yamoc (parte de un par de divinidades de oriente útiles para adorar al sol) y Yamohuanca (parte de una triada, esta era un oráculo). Se encuentran en Huamachuco, cerca al río Chusgón. Creemos que si ya poseen una ubicación definida y claramente adscrita al área de la lengua Culle, a mucha distancia de Lima, no puede haber mayor ligazón. Además, se trata de divinidades secundarias, que se encuentran muy abajo en la jerarquía que encabeza Catequill, la gran huaca oráculo de Huamachuco. Se carece de información acerca del probable significado de esta palabra Yamo.

Las cosas se verán más claras con el cruce de esta información con evidencia arqueológica y etnohistórica enfocada en las influencias o presencias que tuvo la costa y la sierra central del Perú en diversos tiempos.

\section{Conclusiones Preliminares}

La evidencia lingüística manifiesta que algunas divinidades de la costa central, que se hallaron vigentes en el Intermedio Temprano, parte del Horizonte Medio, Horizonte Tardío y tiempos virreinales tempranos, tienen nombres que son más entendibles en lenguas que actualmente son amazónicas. Si bien hemos presentado sólo dos casos, poseemos datos que nos permiten afirmar que el fenómeno es más común de lo que podría pensarse. La toponimia y onomástica de dioses prehispánicos que en quechua o Aru carece de un significado claro tiene mayor sentido cuando se interpreta a través de lenguas del grupo etnolinguístico arawak. Si bien la interacción entre yánesha, asháninka y quechua ha sido constante a lo largo de la historia, no tiene que pensarse en sólo una influencia de Oeste a Este, la narrativa épica yánesha recopilada por Smith $(2004,2011)$ muestra una compleja red de caminos en los que comerciantes, dioses, pueblos, etc. se trasladan de la costa a la selva central y viceversa. Estos caminos han sido recorridos y existe toponimia amazónica que permite corroborar esto desde la lingüística.

Es necesario replantear el estudio de los pueblos costeños prehispánicos en la fuente escrita. La generalizada denominación de 'yunga' se refiere también a pueblos amazónicos, de acuerdo a los informantes de Smith 'yunga' sería una manera de referirse a los 'yoncanesha' pueblo de la costa central que aún no es posible adscribir a un periodo definido, aunque bien pudiera ser usado de modo general para todos los limeños prehispánicos. Trabajos etnográficos del Dr. Toribio Mejía Xesspe informan de variedades de maíz cuyos nombres y descripciones coinciden con las sealadas por los yánesha como propias de esta zona.

La evidencia material que proporciona la arqueología, adecuadamente contrastada con la fuente etnohistórica y etnográfica puede proporcionar importantes resultados en lo que concierne a definición de pueblos, asentamientos y templos. La idea referida a la fuente etnohistórica que sólo puede darnos información hasta el periodo Intermedio Tardío debe empezar a ser desechada. La etnografía está dando resultados que bajan, de modo conservador, como mínimo al Horizonte Medio. Obviamente, el filtrado, depuración, en general el trabajo hermenéutico debe ser extremadamente delicado. 
Desde el punto de vista arqueológico hay que corroborar la información de las fuentes etnohistóricas y etnográficas. Buscar lo que quede de evidencia de los templos de Manañamca (Coraryas) y Amkañ que se ubicarían en el encuentro de los ríos Rímac y Santa Eulalia podría apoyar más la propuesta planteada. Coraryas es un renacuajo o sapo, ¿Hallaríamos imágenes de este tipo en dicho lugar? ¿Se sabe de colecciones particulares de la zona donde este ícono se encuentre representado?

Trabajos pioneros en este sentido han sido absurdamente dejados de lado por motivos que nos son ajenos, desconociéndose de esta manera importantes fuentes tempranas de información cuando el castellano aún no había penetrado con tanta fuerza en la sierra de Lima. Los trabajos de Tello y mejía Xesspe deben ser tomados en cuenta para cualquier trabajo lingüístico sobre Lima en el futuro.

La toponimia constituye una herramienta importante para aproximarnos a pueblos cuyos únicos vestigios que han quedado en cierto espacio geográfico son los topónimos. En este sentido constituyen una fuente histórica aún no aprovechada a cabalidad por arqueólogos e historiadores del pasado limeño.

Se ha planteado desde inicios del siglo XX, con Julio C. Tello, la posibilidad de un sustrato arawak en la costa y sierra de Lima; sin embargo, la idea no ha sido retomada sino hasta el 2011 por Richard Smith quien aporta evidencia etnográfica para sustentar esto. Este tema de investigación debía ser planteado desde una posición netamente lingüística para sustentar la existencia de este aparente sustrato.

\section{Agradecimientos y Pequeño Homenaje}

El autor desea expresar su agradecimiento al Dr. Richard Chase Smith, Director Ejecutivo del Instituto del Bien Común (IBC), por su apoyo al permitirnos utilizar información inédita y revisar parte de este texto. Como es obvio, cualquier error, omisión o problema con este teto es de responsabilidad exclusiva del autor.

Asimismo, al autor desea, mediante este artículo, realizar un sencillo homenaje a la memoria del Señor Espíritu Bautista, sabio yánesha que ahora descansa en la paz de sus ancestros. La recuperación de la historia y valores tradicionales de los pueblos actualmente amazónicos es posible gracias a personas como él, que, lamentablemente, cada vez son más escasas.

\section{BiBLIOGRAFÍA}

ADELAAR, W. F. H.

2008 Reconstruyendo el contacto precolonial entre Andes y Amazonía por medio de datos lingüísticos: El caso de los amuesha de la montaña centroperuana. Leiden: University of Leiden.

BARRETO, María Inés

2012 "Prácticas Sacrificiales en el Valle Bajo del Rímac durante el Período Intermedio Temprano (150-650 d.C)”. Tesis para Obtener el Grado Académico de Magister en Arqueología Andina. UNMSM. P. 268.

BARRETO, María Inés, José Ccencho, Hilda Chuchón y Hernán Silvera

2010 "Sacrificios humanos Lima asociados a la última etapa constructiva de Huaca Pucllana". Arqueología y Sociedad 22. Lima: Museo de Arqueología y Antropología UNMSM. P. 55-72. 
BUSE DE LA GUERRA, Hermann

1977 Época Prehistórica. Historia marítima del Perú. Tomo II, Vol. 1. Lima: Instituto de estudios histórico-marítimos del Perú.

BYNON, T.

1981 Lingüística Histórica. Versión española de José L. Melena. Biblioteca Románica Hispánica Editorial Gredos: 424 Madrid.

DUFF-TRIPP, M.

2008 Diccionario Yanesha' (Amuesha) - Castellano. Ministerio de Educación, Instituto Lingüístico de Verano: 688. Lima.

FLORES ESPINOZA, Isabel

2005 Huaca Pucllana: Esplendor de la cultura Lima. Lima: Instituto Nacional de Cultura.

ROSTWOROWSKI, María

1992 Pachacamac y el Señor de los milagros: una trayectoria milenaria. Lima: Inst. de estudios Peruanos.

2004 Costa peruana prehispánica. Obras completas III. Lima: Instituto de Estudios Peruanos

SMITH, R. CH.

2011 “Un sustrato arawak en los andes centrales? La historia oral y el espacio histórico cultural yánesha”. En: Por donde hay soplo Estudios amazónicos en los países andinos Tomo 29 de la colección Actes \& Mémoires de l'Institut Francais d'Etudes Andines (J. Chaumeil, O. Espinosa \& M. Chaparro eds.): 219-254; Lima: Instituto Francés de Estudios Andinos, Fondo Editorial, Pontificia Universidad Católica del Perú, Centro Amazónico de Antropología y Aplicación Práctica (CAAAP) y Centre "Enseignement et Recherche en Ethnologie Amérindienne" du Laboratoire d'Etnologie et de Sociologie Comparative (EREA-LESC).

Smith, Richard Chase, Wilton Martínez y Espíritu Bautista

2006 Por donde andaban nuestros ancestros. Colección de cuatro videos DVD: Edición Bilingüe Yánesha/Spanish. Lima.

Video 1, RROMAPATSRO: Mapeando el espacio histórico-cultural de los Yanesha. 2006a

Video 2, YATANNNESHAÑ: Recordando a nuestros ancestros. 2006b

Video 3, YOMPOR PARTSESHA: Compasión y transformación en el mundo yánesha. 2006c

Video 4, PORROMNO: Agua, vida y muerte en el mundo yánesha. 2006d

SOLIS F., G.

1997 La gente pasa, los nombres quedan... Introducción a la toponimia. Ediciones Lengua y Socidad. G. Herrera editores: 131 p. Lima

TAYLOR, Gerald

1987 Ritos y tradiciones de Huarochirí del siglo XVII. Lima: Instituto de Estudios Peruanos.

TELLO, J. y P. Miranda

1923 “Wallallo. Ceremonias gentílicas realizadas en la región cisandina del Perú central”. Inca Revista trimestral de Estudios antropológicos. Órgano del Museo de arqueología de la Universidad Mayor de San Marcos. Vol. I, № 2. Editor J. C. Tello: 475-549. Lima. 
TORERO, Alfredo

1990 “Procesos linguísticos e identificación de dioses en los andes centrales". Revista Andina 15 año 8, № 1, julio 1990. Ed. Centro de Estudios Regionales Andinos Bartolomé de Las Casas: 237-257. Cusco.

2002 Idiomas de los andes. Lingüística e Historia. Instituto Francés de Estudios Andinos y Editorial Horizonte: 565 p. Lima.

VARGAS NALVARTE, Pedro

2007 "El tiburón y las olas: apuntes preliminares para un entendimiento de las figuras arqueológicas Lima de Huaca Pucllana (500-700 d.C.)”. Cuadernos de Investigación/INC Arqueología № 1. Lima: Instituto Nacional de Cultura. P. 77-90.

2014 “Lima: donde habita la diosa de la mar". En: Concurso Juan Gunther Investigaciones históricas sobre Lima. Editado por la Municipalidad Metropolitana de Lima. P. 239-245. 